\title{
Periodismo y vida económica local: el diario asturiano El Comercio a principios del siglo XX
}

\author{
Jorge MuÑz SÁNCHEZ \\ Universidad de Oviedo \\ jorgemunizsanchez@gmail.com
}

Recibido: 03/12/2012

Aceptado: 30/04/2013

\begin{abstract}
Resumen
En la España del primer tercio del siglo XX todavía era muy frecuente la prensa partidista, relativamente ajena a la pura competencia informativa en búsqueda de la rentabilidad empresarial. Aquí se pretende esbozar un caso concreto de lo contrario: esa incipiente prensa de negocio, ejemplificada en el diario gijonés $E l$ Comercio. Se tratarán sus cambios técnicos, la evolución en sus criterios periodísticos, su independencia y sus servidumbres o querencias políticas. También se prestará atención a su imbricación y sus relaciones con el tejido productivo local. La prensa como actor destacado de la vida económica de una localidad.
\end{abstract}

Palabras clave: periodismo, Gijón, economía, El Comercio, siglo XX.

\section{Journalism and local economic life: the asturian newspaper El Comercio in the beginning of XXth century}

\begin{abstract}
In the Spain of the first third of XXth century, partisan press was still something really common, being relatively alien to pure information competence in search of corporate profitability. We expect to outline a specific case of the opposite: the incipient press seen as a business, exemplified by the newspaper from Gijón "El Comercio". We will deal with technical changes, the evolution in journalism criteria, its independence, subjection or political inclination. But, especially, we will pay attention to its imbrication and relations with local production network. Press as the leading actor in the economic life of a place.
\end{abstract}

Keywords: journalism, Gijón, economy, El Comercio, XXth Century.

\section{Referencia normalizada}

MUÑIZ SÁNCHEZ, Jorge (2013): "Periodismo y vida económica local: el diario asturiano El Comercio a principios del siglo XX". Estudios sobre el Mensaje Periodístico. Vol. 19, Núm. 2 (julio-diciembre), págs.: 1061-1073. Madrid, Servicio de Publicaciones de la Universidad Complutense.

Sumario: 1. Un diario que cambia. 2. La economía gijonesa en las páginas de El Comercio. 3. Conclusión. 4. Referencias.

\section{Un diario que cambia}

A comienzos de la década de 1910, El Comercio era una publicación que cambiaba con facilidad su estructura, dado que las diferentes partes de la misma carecían de una personalidad lo suficientemente acusada y unas características fijas. Pese a ello, la incipiente especialización de sus rúbricas hacía de él un periódico más ordenado y legible que en etapas precedentes (Fernández Vega, 2004: 169). Esto no quiere decir en absoluto que no hubiera algunos contenidos permanentes, aunque no siempre tuvieran un espacio propio identificable como tal. La portada solía estar ocupada por noticias políticas nacionales y locales, así como, en menor medida, la internacionales, notas de sociedad y sucesos. Puede parecer paradójico que las secciones que empezaban a despuntar y adquirir título y tratamiento diferenciado fueran justamente aque- 
llas más triviales, como las crónicas taurinas o artículos de opinión de colaboradores como el muy recordado Adeflor. Bajo este último pseudónimo, el gijonés Alfredo García fue crucial en la historia de El Comercio. Empezó en 1892, a los dieciséis años, escribiendo como aficionado para acceder a su dirección tras desempeñar todas las funciones imaginables. Fue su máximo responsable desde 1921 hasta su muerte en 1959. Su pluma hábil y de tema variadísimo le hizo también un autor de teatro cómico con cierto renombre en la provincia (Fernández Avello, 1976: 105-106 y Mato, Carmona y Alías, 2004: 7).

La segunda página albergaba normalmente más noticias de la política municipal, sucesos y notas de las otras localidades asturianas, con una atención siempre especial a las mineras. Esto probablemente se debiera a la importancia que el comercio de carbón tenía para el puerto gijonés. De dichas informaciones se ocupaba el corresponsal en Sama de Langreo, Alfonso Muñoz de Diego, conocido concejal reformista que adquiriría el acta de diputado por el Partido Liberal Demócrata en 1933. Los artículos que enviaba a El Comercio solían tener una sensibilidad social especial, tocando desde problemas de vivienda (El Comercio, 19-6-1914; 5-7-1915) hasta conflictos laborales (El Comercio, 10-6-1915). En el mismo lugar aparecía frecuentemente la "Información obrera", que advertía de las novedades en mutuas y sindicatos locales. Igualmente, se introducía "Diversiones", que acercaba una vida mundana de distracciones, principalmente teatrales, que no estaba normalmente al alcance de los trabajadores. Así se ejemplifica de una manera muy gráfica, con estas dos secciones tan próximas en el espacio y tan diferentes, el esfuerzo que siempre hizo el diario, dada su condición de empresa periodística, por llegar al público más vasto que alcanzara. La tercera se ocupaba ya de cuestiones útiles, como la lotería, las cartas al director, las noticias breves, las bursátiles, las religiosas... y curiosamente solían estar organizadas en epígrafes. Una sección muy celebrada, "El Gijón de hace 35 años", apareció en enero de 1917 para recordar noticias antiguas. Agrupar la mayor parte de la publicidad en la última página era algo corriente, en absoluto distintivo del periódico que nos ocupa (Santullano, 1978: 145).

En una publicación que aún contaba solamente con cuatro páginas y por tanto no estaba sobrada de espacio, con una estructura todavía titubeante, es comprensible que el formato mudara fácilmente para adaptarse a las necesidades temporales. Así fue al principio de la Primera Guerra Mundial, que vio incluso la aparición de una edición vespertina para aprovechar el indudable interés que el conflicto suscitaba. Este acontecimiento supuso asimismo una disminución de la calidad del periódico, dado que la voluntad de ofrecer un gran volumen de noticias referidas al mismo -hasta dos tercios en sus primeros compases- obligó a dar entrada a rumores o reelaboraciones de noticias aparecidas en el resto de la prensa, puesto que las nuevas que llegaban de los frentes no resultaban igual de abundantes. A finales de septiembre de 1914, cuando esta atención del público decayó, se suprimió la mencionada edición. Sin embargo, la empresa continuó decidida a obtener el máximo rendimiento de la guerra y en abril de 1917, coincidiendo con el repunte en el seguimiento de la misma por la entrada de EE.UU., se empezó a insertar publicidad en un lugar preferente y llamativo que hasta entonces había permanecido virgen: justo debajo de la cabecera, en una franja rec- 
tangular. Esto coincide justamente con una progresiva complejización de los titulares, que incorporan antetítulo y hasta dos subtítulos para ofrecer mayor información de un solo vistazo y adaptarse a un formato más moderno.

Con todo, estas transformaciones no son tan importantes como las que había experimentado el rotativo en 1911 (Fernández Vega, 2004: 170-171). Será en 1919 cuando asistamos a una reforma comparable a la de ocho años antes, impulsada por la adquisición de cuatro máquinas de componer con las que se podían tirar números de seis páginas para ofrecer más información y también "cultivar una escogida colaboración literaria que anime las columnas de EL COMERCIO" (El Comercio, 15-81919). Este crecimiento no se consolida hasta la Real Orden de junio de 1920 duplicando el precio de los periódicos, que pasan a costar $10 \mathrm{cts}$., dado que hasta entonces fueron relativamente frecuentes aún los números de cuatro páginas. Todavía en agosto de ese año se vuelve a las cuatro planas por dificultades para abastecerse del papel adecuado para las hojas centrales (El Comercio, 19-8-1920), no recuperando la media docena hasta la llegada de Adeflor a la dirección, en 1921, gracias al descenso del precio de la celulosa (El Comercio, 21-5-1921). Seguramente como respuesta, el tercer diario local, La Prensa, comenzó a contar ocho páginas en ese 1921 (Santullano, 1978: 145). Se adoptó entonces un diseño de portada más ágil, con mayor número de temas que con frecuencia sólo ocupaban cinco o seis líneas y unos titulares de tamaño creciente a partir de las noticias de la huelga minera de octubre de ese año y que obviamente estaba destinado a llamar la atención de los potenciales compradores. Igualmente, se inició un mejor uso de líneas, recuadros y espacios -hasta entonces escasísimos- y se empezó a numerar las páginas, amén de incorporar una cabecera en la última. Todo ello confirió una mayor claridad al conjunto. Hubo un pequeño paréntesis en el que el formato adquirió unas formas llamativas y que están por esclarecer, dado que no ofreció ninguna explicación a un cambio que no era el anunciado. El 21 de septiembre de 1919 se publicó con doce páginas de aproximadamente la mitad de tamaño que hasta entonces, acercándose así al formato tabloide. No se pudo mantener, por falta de bobinas de papel de esas medidas. Lo normal en la época eran las grandes dimensiones, resultando El Comercio $(90$ por $61 \mathrm{~cm}$.) el más amplio y El Noroeste (56 por 40) el más manejable (Santullano, 1978: 145).

La distribución de las secciones no varió sustancialmente y en general aumentaron la publicidad, la información y las colaboraciones de ciudadanos relevantes que fueron llamados a participar en una "Tribuna Libre" con propuestas para superar el problema hullero. Sin embargo, disminuyeron los artículos periodísticos que tan frecuentes habían sido hasta entonces, algo en consonancia con los nuevos tiempos, más propicios a la labor del reportero como productor de noticias (Santullano, 1978:145). Otro cambio, si bien en este caso paulatino, fue la sustitución de los toros y la aviación -más aristocráticos- por el fútbol en los deportes, amoldándose así a la modificación de los gustos mayoritarios. El balompié fue introduciéndose con crónicas de partidos de los equipos locales, entre los que se hallaba ya el Sporting Gijonés (El Comercio, 27-11-1916). Después, ocupando cada vez más espacio, describiendo jugadas e introduciendo noticias del fútbol nacional incluso en la portada (vg. El Comercio, 14-5-1917). Posteriormente se produjo la complicación de las informaciones, 
apareciendo las alineaciones según la distribución de las líneas en el campo (julio de 1919), las clasificaciones de los campeonatos en tablas de puntuación (noviembre de 1920) y las entrevistas a jugadores (julio de 1924). Finalmente, se decidió la publicación de análisis previos de cada jornada (octubre de 1930) y amplios resúmenes posteriores de la misma con atención a cada encuentro (octubre de 1935). No sólo se dio un crecimiento relativo del fútbol: la información deportiva en su conjunto aumentó notablemente su tamaño y mejoró su presentación mediante logotipo propio desde julio de 1921.

Este conjunto de modificaciones tan importante fue redondeado en 1920 introduciendo un chiste gráfico a cargo de Manolo Tovar en la portada, además de un par de secciones de comentarios jocosos de actualidad. Una de ellas estaba firmada por Francisco Serrano Anguita, Tartarín, un autor teatral cómico de cierto éxito, circunstancia que $\mathrm{El}$ Comercio no desaprovechó para autopromocionarse. También aumentaron en la portada las noticias sobre política nacional y en los recuadros a los extremos de la cabecera de los que se habían eliminado los precios empezaron a anunciarse contenidos interiores y, desde agosto de 1932, a publicarse los números de teléfono de $\mathrm{El} \mathrm{Co-}$ mercio, símbolo de modernidad. En la segunda aparecían las noticias de Gijón y sociedad, en la tercera la información parlamentaria y los deportes, en la cuarta "El Comercio por la provincia" -la sección de información local ampliada-, en la quinta la última hora, la información marítima y unos dos tercios de publicidad incluyendo los anuncios clasificados y en la sexta únicamente anuncios. Por estas fechas (julio de 1920) se comienza también a ofrecer una o dos páginas referidas a localidades que celebrasen sus fiestas patronales. Glosando las fiestas, la economía local y los atributos turísticos del lugar daban pie a la publicidad directa o indirecta. Pronto estas informaciones supondrán el aumento del número usual de páginas, para no restar espacio al resto. La apoteosis, obviamente, se producía el 15 de agosto, día de Begoña, con un número extraordinario que en 1923 constó de veinte páginas y más de sesenta fotos, anunciado con varios días de antelación.

Probablemente el aspecto más destacado de todo este cambio sea la decidida incorporación del elemento gráfico al diario. Los chistes de Tovar se ubicaron permanentemente bajo la cabecera, en el lugar más llamativo, y fueron pronto acompañados por la sección "La caricatura en el extranjero", que recogía viñetas de publicaciones internacionales. El joven gijonés Pepe Álvarez Sala inició la publicación de "La caricatura del jueves" en 1925, paliando así la irregularidad del tradicional chiste de Tovar, que a menudo faltaba y en otras ocasiones consistía en un dibujo ya publicado con un diálogo nuevo, probablemente por falta de disponibilidad del autor a causa de sus otras ocupaciones. Pero será la fotografía la innovación estrella. En un principio se basaba en imágenes de estudio de personajes relevantes (verano de 1920) y pronto evolucionó hacia fotos de calle y deportivas (primavera de 1921), que incluso empezarán a ser tomadas en acción en lugar de posadas (julio de 1921). La ambición inicial, con casi un retrato por página, fue decayendo sin duda a causa del alto coste de las ilustraciones, pero se mantuvo en ratios bastante elevadas. En 1921 incluso se incluían algunas imágenes descontextualizadas, comúnmente de motivos locales. De modo semejante, en los años treinta se publicaban fotogramas de películas con ape- 
nas un pie con su nombre y lugar de exhibición, aunque en este caso habría también sin duda una finalidad publicitaria. El desembolso que suponían unos talleres de fotograbado trató de rentabilizarse haciendo encargos particulares. La irrupción de la imagen en sus diversas manifestaciones contribuía a volver el periódico más accesible a sectores populares. Sin embargo, llegó con cierto retraso respecto a competidores locales que introducían ya viñetas humorísticas y fotografías hacia 1910. Cabe aventurar que esta renuencia de El Comercio, semejante a la que mostró el ovetense El Carbayón, se deba a su orientación preferente hacia la clase media alta, menos necesitada de apoyos gráficos a la lectura y que incluso podría considerar de mal gusto algunas sátiras (Díaz González y Campo, 2004: 447 -452). Sea como fuere, El Comercio introdujo sus innovaciones en este campo con la mayor de las prudencias: la primera caricatura de Álvarez Sala fue de él mismo, para dar ejemplo de sentido del humor con la petición expresa de que nadie se tomara a mal las que se publicaran en lo sucesivo, que serían hechas con todo el respeto (El Comercio, 23-4-1925). El resto de cambios que se introdujeron fueron de menor importancia y no existe en el período aquí estudiado una batería de modificaciones comparable a la que se ha detallado. Por ejemplo, en febrero de 1922 se inaugura el moderno recurso, para optimizar el espacio de la portada, de empezar noticias en ella y terminarlas en el interior. Novedad reseñable es asimismo el intento por atraer lectoras con la sección "Crónicas femeninas", consistente en consejos y tendencias de moda que se empiezan a insertar en febrero de 1924.

Como se ha indicado ya, El Comercio ha sido siempre un rotativo de negocio, con un fin lucrativo primordial. A diferencia de otras cabeceras cuyo objetivo era político por servir a los intereses de algún partido o facción y que por tanto podían incluso permitirse perder dinero para servir a éstos, el diario que nos ocupa tuvo siempre en la rentabilidad su horizonte inequívoco. Esto se refleja en la gran cantidad de estrategias de autopromoción que puso en práctica a lo largo de su historia, empezando por los regalos que en 1911 y coincidiendo con la primera gran remodelación señalada quiso distribuir entre sus lectores (Fernández Vega, 2004: 170). Como buena publicación periódica en busca de fidelización, la emisión de cupones cuya colección daba derecho a entradas para espectáculos o sorteos de premios en metálico fue frecuente. En 1914 se otorgaron 2.500 ptas. en varios premios, dando una participación por cada 15 cupones (El Comercio, 13-9-1914). Un par de años más tarde se sortearon 250 ptas. entre los acertantes de los diputados que serían proclamados por Asturias. Esta práctica se repetía una o dos veces al año. También se rifaron entradas para un partido de fútbol Italia-España a celebrar en Gijón y que suscitó gran expectación o para las corridas de Begoña (El Comercio, 25-3-1928 y 22-4-1930). Sin el interés crematístico, pero con igual concepto de coleccionable, ideal para los fines expuestos, se adoptó con entusiasmo la costumbre de publicar un folletón por entregas que ocupaba la parte baja de la última página. Se ofrecían obras populares, como El rey de los gavieros, del popular folletinista francés Ernesto Capendu, que se comenzó en octubre de 1914. Pero también novelas que, sin dejar de resultar atractivas para el gran público, atesoraban una indudable calidad literaria, como Cinco semanas en globo, de Julio Verne (El Comercio, 9-7-1936 y sucesivos). La idea de anticipar contenidos futuros haciendo 
expresa la fecha de su publicación se abrió paso igualmente en esa línea de fidelizar a la clientela. Un ejemplo en esta línea pueden ser las bodas de oro de El Comercio, el 2 de enero de 1927, en un número que contó con gran cantidad de trabajos literarios y artísticos, fotos y veinticuatro páginas, todo ello anunciado a diario con dos meses de antelación.

Ensalzar las propias cualidades, reales o supuestas, fue asimismo un recurso frecuente. Destacar los magníficos locales en la calle Corrida, en el centro de la ciudad, los periodistas o colaboradores de gran prestigio, los modernos medios técnicos... todo era útil para el fin perseguido. La imagen de solvencia resultaba capital y en ello "la casa" que ocupaba físicamente un negocio era importante como símbolo de su solidez. En este sentido debe interpretarse el anuncio de reformas en el local (El Comercio, 25-4-1917) a cargo del conocido arquitecto Manuel del Busto. En estrecha relación con lo anterior podríamos mencionar la voluntad por aparecer como miembro destacado y benefactor de la comunidad que, por ejemplo, organiza cuestaciones en favor de los soldados asturianos en África (El Comercio, 11-11-1921, 18-9-1923).

Dentro del género igualmente bélico, pero en este caso puramente periodístico, se aprovecharon coyunturas informativas especiales, como los momentos más críticos de la empresa colonial española de la época, gracias a que los enviados de El Comercio a Melilla descubrieron un filón en investigar el paradero y publicar informaciones breves sobre los soldados asturianos allí destacados cuyos familiares lo requirieran (vg. "Encontramos el cadáver del teniente gijonés", El Comercio, 3-11-1921). En semejante línea, tampoco el género periodístico "amarillo", de sucesos, fue ajeno a esta estrategia comercial, motivo por el cual tragedias particulares aparecían con frecuencia en portada. Entre el 20 de octubre y el 5 de noviembre de 1915, se dedicó incluso a hacer campaña contra la condena a una madre que consideraba inocente del asesinato de su hijo con polémica incluida con La Voz de Avilés, por lo que esta última consideraba un injustificado descrédito a la justicia. En menor medida, también el mundo "rosa" tenía acogida, si bien por el momento circunscrito en exclusiva a la vida privada de los grandes toreros (vg. El Comercio, 17-6-1914) y al seguimiento de las actividades diarias de la familia real ("Triunfo del Rey en el tiro de pichón", El Comercio, 25-5-1915).

En último lugar, cabe aludir también aquí a la política de precios, que implicaba una cautelosa gestión informativa de todos los aumentos, que se establecían por acuerdo con los competidores locales o por orden gubernativa (El Comercio, 20-6-1916, 166-1920, 22-3-1932) para satisfacer las necesidades creadas por lo gravoso del papel. En algún caso, como el incremento por ley a 15 céntimos, anunciado el 31-5-1935, el rotativo trató de aprovechar la ocasión para acrecentar sus suscriptores, ya que el decreto le permitía mantener los precios de los abonos y así lo hizo y anunció profusamente (El Comercio, 27-6-1935 a 27-7-1935).

El periodismo entendido como negocio aconsejaba la no adscripción explícita del diario a ningún partido político para poder optar a un público lo más nutrido posible. Sin embargo, esto no quiere decir que fuera ajeno a toda motivación de este tipo, sino simplemente que tomó parte en las querellas políticas de una forma más sinuosa, menos evidente por lo general, y que además le permitía hacer gala de una gran cin- 
tura para variar sus preferencias según aconsejaran las circunstancias, sin verse encorsetado en ninguna fidelidad partidista que le obligara demasiado o resultara excesivamente estable y evidente. Por este motivo, tras haber apoyado sucesivamente a los dos partidos turnantes, con la crisis de la Restauración pasó a engrosar con entusiasmo el reformismo del prócer local Melquíades Álvarez. Esto se manifestó en generosos elogios al líder reformista de Avilés, José Manuel Pedregal: "Por diputados así, suspiramos [...]", (El Comercio, 25-3-1916) y en la corresponsalía en Sama de Langreo que concedió al anteriormente citado Alfonso Muñoz, a la sazón concejal melquiadista. Pese a ello, y por idénticas motivaciones, no tuvo el más mínimo reparo nuestro diario en convertirse al conservadurismo autoritario a partir de 1917, cuando el miedo a la conflictividad social se hizo más acuciante en los sectores de la buena sociedad gijonesa que lo promocionaban. Por supuesto, esto incluyó un decidido y temprano apoyo a la dictadura de Primo de Rivera (véase, por ejemplo, el editorial del 14 de septiembre de 1923). Entonces comenzó a afear al Partido Reformista su travestismo político, que le permitía captar votos en sectores obreros y burgueses, monárquicos y republicanos, gracias a lo que el rotativo consideraba peligrosa indefinición: "quita y pon de gorro frigio y corona" (El Comercio, 14-2-1925). Con la llegada de la Segunda República estas tendencias se acentuaron y el periódico participó de forma agresiva en las campañas llevadas a cabo por la Acción Popular de Gil Robles. En las mismas existieron tres ejes básicos de argumentación: la cuestión territorial, la reforma agraria y la conflictividad social. De todo ello se culpaba a la izquierda y se aseguraba que había que "orientar la República" (Muñiz Sánchez, 2007). Tras el estallido de la Guerra Civil, El Comercio fue incautado por las autoridades republicanas, siendo publicado dos veces por semana entre agosto y diciembre de 1936 con una línea anarquista para desaparecer luego para ser utilizadas sus instalaciones por el socialista Avance y finalmente, tras la conquista de Gijón por los facciosos, ser devuelto a sus propietarios y recuperar el tono militantemente derechista de la época anterior, si bien tamizado ya por la orientación filofascista de la primera etapa del franquismo (Mato, Carmona y Alías, 2003: 449 y 454).

\section{La economía gijonesa en las páginas de El Comercio}

El Comercio estuvo siempre preocupado por la salud de la industria hullera regional porque de ella dependían en buena medida los intereses del puerto local, que distribuía una parte nada despreciable de la producción. Tampoco es ajena esta especial atención prestada por el rotativo a personalidades locales, como Óscar Olavaria o la familia Alvargonzález, que eran socios fundadores de $E l$ Comercio. Por eso a menudo, cuando se decía defender los intereses de la villa, se estaba en realidad mirando por los de estos patronos en particular (Alvargonzález, 1985: 45-49, Santullano 1978: 149, Fernández Vega, 2004: 177). Por idéntico motivo se seguía con celo todo lo tocante a las comunicaciones de la dársena con las cuencas hulleras. Esta preocupación estaba plenamente justificada por una insuficiencia histórica que se vio exacerbada por las explosivas necesidades determinadas por la guerra. El periódico calculaba en este trance que el carbón que se cargaba era un cuarenta por ciento del que hubiera sido necesario y denunció lo que entendía escasez de vagones disponibles para el transporte en 
el Ferrocarril del Norte. También demandó que se prohibiera la exportación de material ferroviario y exigió la electrificación de la rampa de Pajares, cuya realización agradeció muy vivamente a Cambó (El Comercio, 1-11-1916, 2-10-1916, 15-10-1916, 30-6-1918). Prueba de lo sentida que era esta última reivindicación, símbolo de las constantes demandas de comunicación de la región, es que hoy en día todavía figure en lugar preferente de la estación ferroviaria de Oviedo una placa reconociendo al político catalán su concurso en la realización de la obra. Resultó igualmente motivo de preocupación el estado en que se encontraban los puertos de Gijón, fuente de conflictos con la Junta de Obras a propósito, por ejemplo, de los retrasos en los trabajos del dique Norte (El Comercio, 12-3-1925). Sin ir más lejos, en 1930 se acusó a dicho organismo de pretender cegar el puerto interior con maniobras dilatorias para no dragarlo (El Comercio, 6, 7 y 8-3-1930).

Pero sin duda el centro de los conflictos fue El Musel y la polémica más seria se produjo con motivo del cese del Director Facultativo de la Junta de Obras. El Comercio fue acusado por el destituido de llevar a cabo una campaña en su contra a causa de su oposición a la venta al Estado de los muelles de la Sociedad Fomento de Gijón en las condiciones que pretendían sus propietarios, algo que dejaba muy en entredicho la credibilidad e independencia de la publicación y que ésta se empleó a fondo en negar (El Comercio, 24-1-1932, 30-1-1932 y 31-1-1932). El éxito de El Musel dependía en parte de que se lograra para el mismo algún régimen fiscal favorable: una zona neutral fue la primera opción por resultar la más ventajosa para las actividades allí desarrolladas, pero pronto se hizo campaña por el depósito franco - que finalmente fue aprobado - vista la dificultad de obtener aquella. Por cierto, que no se dejó pasar la ocasión para criticar al gran competidor local, el diario El Noroeste, por confundir, en opinión de los responsables de la publicación que nos ocupa, zona neutral y depósito franco (El Comercio, 30-11-1914, 1-12-1914, 2-12-1914, 7-12-1914, 812-1914, 10-12-1914 y 20-11-1915).

Otro elemento portuario que mereció las atenciones del rotativo fue el mantenimiento del tráfico de pasajeros, por lo que aplaudió el establecimiento de nuevas líneas transatlánticas, como la que uniría el Norte de España con Nueva York ( $E l$ Comercio, 25-9-1915, 18-10-1915 y 21-11-1915). Para defender esta línea y otras estuvo siempre atento, denunciando los frecuentes intentos de omisión de la escala gijonesa en estos viajes en provecho de otros puertos cantábricos (El Comercio, 6-12-1915, 10-12-1915, 15-4-1916, 21-4-1916, 28-5-1916, 18-8-1916, 30-6-1919, 46-1920 y 30-10-1920, entre otros). En efecto, periódicamente se aireaba en determinados mentideros la posibilidad de inhabilitar el puerto gijonés como centro de embarque de emigrantes, algo a todas luces ridículo porque la gran diáspora asturiana hacia América garantizaba su viabilidad. El diario temía que los intencionados olvidos de la escala de Gijón, que obligaban a los asturianos a desembarcar en Santander, acabaran por reducir significativamente las cifras de pasajeros de El Musel, que eran precisamente el principal argumento de defensa de éste. Por eso estuvo siempre muy atento, protestando contra la supresión de inspectores de emigración, denunciando la morosidad en levantar el estado epidémico en algunos concejos que hacía disminuir el flujo de emigrantes hacia el puerto, exigiendo obras para adecuar El Musel y, por 
supuesto, reaccionando airado contra cualquier propuesta o insinuación de retirada de la habilitación de que gozaba la villa (El Comercio, 6-12-1916, 16-1-1917, 12-1-1919, 19-1-1919, 26-1-1919). Llegó a proponerse la creación de una flota transatlántica asturiana para solventar todo esto que el periódico juzgaba conspiraciones y dado que se estimaba que el futuro de Gijón dependía del puerto (El Comercio, 28-1-1919). Claro que también, aunque esto no se decía, pendían de un hilo los intereses de algunos de los propietarios de la publicación que debían su fortuna al negocio naviero. Pese a todo, durante una de las polémicas que ambos protagonizaron, El Noroeste acusó a El Comercio de dejación a la hora de denunciar el salto de las escalas por la Compañía Transatlántica Española para no quedarse sin un anuncio de la misma que el diario reformista había "perdido por defender a Gijón y a Asturias dignamente" ( $E l$ Noroeste, 6-2-1925).

Si las cuitas marítimas fueron un elemento destacado en las páginas de $E l$ Comercio, tampoco las comunicaciones ferroviarias y por carretera estuvieron fuera de las mismas: se trataron las conexiones con Oviedo (por tranvía, El Comercio, 30-1-1915, y autopista, El Comercio, 1-3-1932), las vías férreas hacia León (El Comercio, 11-31916, 17-12-1917) o hacia la cuenca del Nalón (protesta por el abandono de la línea San Martín-Lieres-Gijón-Musel, El Comercio, 19-11-1927) o la exclusión del tramo Ribadesella-Canero del Circuito Nacional de Firmes Especiales de Carreteras ( $\mathrm{El} \mathrm{Co}$ mercio, 14-10-1926 y 15-9-1932). Sin embargo, el caso estrella fue el del Ferrocarril Ferrol-Gijón, un proyecto importante que se demoró años y conoció todo tipo de vicisitudes, siempre bajo la atenta mirada de la redacción de El Comercio desde que se sumara a la iniciativa del alcalde de Vegadeo, Everardo Villamil en 1903. Durante la Primera Guerra Mundial se rescató la idea, que resultaba conveniente para comunicar los arsenales gallegos con el puerto de Gijón. Se constituyeron asociaciones y un lobby asturgalaico de diputados, se celebraron manifestaciones... (El Comercio, 26-10-1914, 28-11-1914, 21-5-1915, 19-7-1915, 31-5-1915, 28-7-1915, 1-8-1915). Pero lo más sorprendente de esta etapa fue sin duda la reacción del diario contra la Cámara de Comercio de Oviedo por omitir esta vía férrea en un informe sobre las infraestructuras carboneras necesarias (El Comercio, 1-3-1916, 24-3-1916 y 18-4-1916). Se antoja evidente, por más que el diario lo defendiera, que un ferrocarril por la costa occidental de la provincia no tenía demasiada utilidad para el sector hullero. Finalmente y tras múltiples gestiones infructuosas en busca de una empresa concesionaria, el Estado se hizo cargo de la misma de forma directa en 1920, subastándose inmediatamente varios tramos y comenzando la construcción en 1921 (Gómez Martínez, 1999: 22 y 26-27).

Aprobado el proyecto, El Comercio se autoproclamó garante de la realización fiel del mismo, criticando las faltas o reducciones de presupuesto, que normalmente iban unidas a los intentos de variar el trazado apoyándolo en vías ya construidas. Así sucedió cuando el periódico local La Prensa intentó infructuosamente favorecer un transbordo en el Ferrocarril de Carreño para reducir los costes, algo que hubiera sin duda empeorado la calidad y la rapidez del servicio, que hubiera dejado de ser directo. Por eso El Comercio siempre defendió que se empezara la construcción por el tramo Gijón-Avilés, que era precisamente el que se veía amenazado por estas intrigas ( $E l$ 
Comercio, 26-5-1920, 27-5-1920, 1-6-1920, 2-3-1922, 4-4-1922). Con todo, la cuestión principal fueron realmente los intentos de desviar el tráfico hacia el interior en el centro de la región para hacer innecesaria la construcción del Ferrocarril de las Cinco Villas - continuación costera del ferrolano hasta Ribadesella — porque el viaje hacia el Oriente podría continuarse empalmando a través de Oviedo con el Vasco-Asturiano. Tales pretensiones suscitaron las iras del periódico gijonés y alimentaron una larga y farragosa polémica con el ovetense Región (El Comercio, 7-9-1922, 12-9-1922, 18 10-1922, 12-12-1925, 27-12-1925, 29-12-1925, 30-12-1925, 31-12-1925, 2-1-1926, 7-1-1926, 8-1-1926, 13-1-1926, 13-11-1926, 14-11-1926, 19-11-1926, 21-11-1926, 18-11-1927). En este empeño el diario gijonés fue derrotado, porque finalmente el trazado fue variado en Pravia para favorecer el encuentro con el Vasco en esta localidad tras estudios técnicos encargados por el gobierno (Gómez Martínez, 1999: 44). Además, sus encendidos artículos acabaron por ser objeto de censura (El Comercio, 10-2-1927 y 3-5-1927). Pero no terminarían aquí los problemas experimentados por esta obra: con la crisis de los años treinta se retrasó para reanudarse a principios de los cuarenta y terminarse en 1972 (El Comercio, 17-1-1932, 9-8-1932, 10-4-1935, 27-51936; Gómez Martínez, 1999: 27 y 72).

El Comercio encontró en la defensa de las instituciones radicadas en la ciudad otro elemento de preocupación constante que a menudo le llevó a confrontar con las pretensiones de Oviedo en esos ámbitos: la pugna por la exclusividad regional de la Escuela de Industrias (El Comercio, 6-9-1915, 7-9-1915, 20-9-1915, 28-9-1915 y 21-6-1918), el traslado a la capital de la oficina del catastro de Gijón (El Comercio, $18-8-1926)$ y la distribución del presupuesto de la Diputación para los municipios (El Comercio, 27-12-1930) fueron otras tantas ocasiones para manifestar este celo. Claro que donde más nítidamente se apreciaban estas desavenencias localistas era precisamente en polémicas con escasas o nulas repercusiones económicas para los interesados, como la largo tiempo sostenida en torno al cambio de denominación oficial de la provincia de Oviedo a Asturias (El Comercio, 2-6-1926, 5-6-1926, 6-6-1926...).

Pese a la impresión que pueda extraerse de lo mencionado hasta aquí, no todas las acciones del periódico en defensa de intereses locales fueron a la defensiva, respuesta a agresiones reales o supuestas. También incluyeron iniciativas novedosas, como el establecimiento de la Feria de Muestras de Asturias en la ciudad, idea que lanzaba Adeflor allá por 1917 tras una visita a Valencia:

“ $i$ Con cuántos más elementos cuenta Asturias para una Feria-Muestrario, verdadera exposición de los productos regionales! Ya brindo la idea a los Presidentes de la Cámara de Comercio, del Círculo Mercantil y de la Unión de los Gremios de Gijón" (El Comercio, 295-1917).

A partir de entonces, el diario siguió de cerca el proceso que culminó con la creación de la Feria de Muestras de Asturias, sobre todo en su fase final (El Comercio, 315-1923, 1-6-1923, 10-5-1924). La primera edición se celebró en la segunda quincena de agosto de 1924 en el Paseo de Begoña (Álvarez García, 2000: 391).

El turismo, su promoción y desarrollo, fue otra de las grandes preocupaciones que se asomaron a las páginas de la publicación que nos ocupa. De ahí que, por ejemplo, 
se reclamara insistentemente el traslado del Hospital de Caridad, que obstaculizaba el embellecimiento y el desarrollo urbanístico de la zona más próxima a la playa. Se defendió que las ganancias derivadas de la operación urbanística con el solar de la institución fueran la base de la financiación de uno nuevo que habría de construirse en el extrarradio. En el espacio liberado en el centro de la ciudad habría de ubicarse un "Hotel-Balneario-Teatro-Casino", considerado crucial para el despegue del sector turístico local (El Comercio, 23-3-1929, 24-3-1929, 26-3-1929, 27-3-1929, 2-4-1929, 44-1929, 6-4-1929). Desde años atrás el periódico venía defendiendo la necesidad de este centro de ocio, puesto que ya en 1921 criticaba la negativa del Ayuntamiento a conceder terrenos para este fin sobre la playa (El Comercio, 25-2-1921).

Como inspiración en el ámbito de la promoción turística, El Comercio tomó como ejemplo lo que sucedía en lugares como Santander o San Sebastián, donde el veraneo de la familia real constituía un auténtico espaldarazo mediático con impacto en todo el país. Por este motivo se describía minuciosamente cada visita de algún borbón, como por ejemplo las venidas del rey a las regatas (El Comercio, 8/14-7-1914). Por idéntica causa se atacaba con saña a quienes criticaban las subvenciones al Club Astur de Regatas, cuya función en este contexto se consideraba que trascendía ampliamente el mero fomento del deporte (El Comercio, 24-11-1916). En cualquier caso, no debe olvidarse que se trata de un periódico monárquico y por tanto naturalmente inclinado a este tipo de informaciones. Ello explica también que reaccionara virulentamente cuando la realeza española sufrió algún desplante institucional en la ciudad, como la negativa de la corporación municipal a asistir a la jura de bandera del heredero, a la que había sido invitada (El Comercio, 10 y 12-6-1920). Conviene igualmente no menospreciar otra vertiente en auge de estas noticias: su efectividad como crónica social de alto nivel, ancestro de la actual información rosa. En este caso es digno de mención el cambio de opinión del rotativo, que pasó de bromear con la idea de unos particulares de pedir un palacio para el Príncipe de Asturias en Gijón porque se consideraba que la ciudad estaba abandonada y no era digna (El Comercio, 2-9-1919 y 4-9-1919) a adherirse con motivo de la mayoría de edad del príncipe (El Comercio, 6-5-1923). De todas maneras, lo que siempre tuvo claro el diario fue que se debía "extremar el afecto al monarca, dejándonos todos las ideas políticas en los bolsillos, para atender los intereses locales y provinciales [...]" (El Comercio, 9-7-1914). La voluntad de emular a las otras dos ciudades norteñas mencionadas se manifestó también en la propuesta de edición y distribución a escala nacional de portfolios de promoción del verano gijonés, tal y como hacían ellas (El Comercio, 27-3-1915). Claro que en esto podía existir un interés añadido al poseer el diario una imprenta propia... En la misma dirección, se conminaba a mejorar la organización y promoción de las fiestas veraniegas y de carnaval, cuya improvisación se consideraba parte del abatimiento generalizado que se creía constatar en las instituciones locales (El Comercio, 24-2-1916, 4-4-1918, 8-4-1918).

\section{Conclusión}

En un momento de profundas transformaciones en el mundo del periodismo, cuando está franqueando los pasos que van a convertir la prensa escrita en un medio de masas, o al menos mucho más popular de lo que era hasta ese momento, las cabeceras locales 
no permanecen ajenas a estas tendencias. En el caso que aquí se estudia nos encontramos con una decidida voluntad de modernización técnica que permita poner al diario en condiciones de competir con los más avanzados en esta materia, ofreciendo un formato atractivo, reduciendo costes, ampliando paginación o mejorando el rendimiento publicitario. También se pondrá una atención creciente en la captación y la fidelización de la clientela por medios que poco a poco adquirirán una complejidad notable $y$, de algún modo, anticipan técnicas todavía empleadas hoy en día bajo una u otra forma. Así, los reclamos tipográficos, el nuevo estilo periodístico en el que el artículo de fondo va dejando espacio a textos de tipo más reporteril o las diferentes expresiones gráficas toman al asalto sus páginas y transforman en unos pocos años el rotativo de una manera sumamente visible si se contempla el proceso en su conjunto. Esto permitirá acceder a sectores mayores de la población que no disponían del bagaje cultural ni del interés necesario para apreciar los usos y costumbres anteriores. Se masifica, por tanto. En este sentido, resultará inevitable que nuevos temas hasta entonces considerados banales copen progresivamente la atención. Ejemplo destacado es la información deportiva, que crece de manera destacada a la vez que el peso relativo del fútbol en la misma se dispara. Algo perfectamente lógico y en consonancia con la importancia social que el balompié adquirirá en este período, desbancando a los elementos clásicos del sector, como los toros o los deportes tradicionales y aristocráticos. También se desarrolla el sensacionalismo, buscando atraer al comprador desde la portada con noticias que en muchos casos no trascienden el ámbito de lo personal y lo privado.

Semejantes innovaciones, que colocan al diario en el horizonte cotidiano de muchas más personas que antaño, lo convierten a la vez en un instrumento poderoso en el ámbito local. En el plano político, por supuesto, porque aunque El Comercio permaneció independiente formalmente y con una cierta capacidad de evolución política que le permitió adaptarse a los cambios de todo tipo a los que se vio confrontado, no dejó por ello de prestar servicio a las ideas que sus promotores profesaron y de un modo mucho más efectivo a buen seguro que si lo hubiera hecho de una manera más expresa. Pero también desde un punto de vista económico, puesto que los intereses de la ciudad estuvieron siempre en el credo periodístico de esta cabecera. Los de Gijón, pero mucho más particularmente los de los grupos socioeconómicos que de una manera más o menos directa lo sostenían. Ambos ámbitos tendían además a confundirse de una manera interesada: con frecuencia se presentó como deseable para el bien común de la villa lo que lo era sin duda beneficioso para los dueños del periódico, muy vinculados al sector naviero.

\section{Referencias}

ÁLVAREZ GARCÍA, Manuel (2000): "Los años veinte en Gijón”, en ÁLVAREZ ALÍAS, Luis Antonio: Historia de Gijón. Gijón, El Comercio.

ALVARGONZÁLEZ, Ramón María (1977): Gijón: industrialización y crecimiento urbano. Salinas, Ayalga.

ALVARGONZÁLEZ, Ramón María (1985): Industria y espacio portuario en Gijón. Gijón, Junta del Puerto. 
BONET, Joaquín A. (1959): Proyección nacional de la villa de Jovellanos. Gijón, La Industria.

DÍAZ-FAES INTRIAGO, Manuel (1979): La minería de la hulla en Asturias. Oviedo, Universidad de Oviedo.

DÍAZ GONZÁLEZ, María del Mar y CAMPO, Orlando (2004): "La ilustración gráfica y la fotografía en la prensa periódica asturiana (1880-1914)", en URÍA, Jorge: Historia de la prensa en Asturias, tomo I, Nace el cuarto poder. La prensa en Asturias hasta la Primera Guerra Mundial. Oviedo, Asociación de la Prensa de Oviedo.

FERNÁNDEZ AVELLO, Manuel (1976): Historia del periodismo asturiano. Salinas, Ayalga.

FERNÁNDEZ VEGA, Carmen (2004): "El diario El Comercio (1878-1914)", en URÍA, Jorge: Historia de la prensa en Asturias, tomo I, Nace el cuarto poder. La prensa en Asturias hasta la Primera Guerra Mundial. Oviedo, Asociación de la Prensa de Oviedo.

FLORES SUÁREZ, José María (2004): El Ferrocarril de Langreo: estaciones e infraestructura. Gijón, Trea.

GARCÍA QUIRÓS, Paz y FLORES SUÁREZ, José María (2000): Gijón, la ciudad del vapor. Historia de la industria y el comercio. Gijón, GEA.

GÓMEZ MARTÍNEZ, José Antonio (1999): El ferrocarril Ferrol-Gijón. Gijón, Trea.

MATO, Ángel; CARMONA, José Luis; y ALÍAS, Luis Antonio (2003): Testigo de la historia. 125 años. El Comercio 1878-2003. Gijón, El Comercio.

MUÑIZ SÁNCHEZ, Jorge (2007): "Prensa local y radicalización política ciudadana: el diario asturiano El Comercio hacia la guerra civil", en Estudios sobre el Mensaje Periodístico, n. ${ }^{\circ}$ 13. Madrid, Servicio de Publicaciones de la Universidad Complutense.

OJEDA, Germán (1985): Asturias en la industrialización española, 1833-1907. Madrid, Siglo XXI.

SANTULLANO, Gabriel (1978): "La prensa desde 1898 hasta 1920", en ARIAS, Arturo: Historia general de Asturias. Gijón, Silverio Cañada. 